\title{
A STUDY ON THE ULTRAVIOLET FINISH ON MODAL /COTTON KNITTED FABRIC USING BIOPOLYMER
}

\author{
Suganthi.S ${ }^{1} \&$ Dr.k.Pachiyappan ${ }^{2}$ \\ 1.(Ph.D scholar), Department of Costume Design \& Fashion, PSG College of Arts and Science, Coimbatore. \\ 2.The Head, Department of Costume Design \& Fashion PSG College of Arts and Science, Coimbatore.
}

\begin{abstract}
The well-being of human skin in opposition to ultraviolet radiation is extremely important problem and over current years researches have exposed an increasing curiosity in this field. The growing customer consciousness of the probability of the sun has partial textile industry. This research investigation, the treated and untreated specimen are distingush using FESEM and FT-IR. The value of the treatment is evaluate using the regular tests, such as the ultraviolet protection and UV visible spectrophotometer elements both before and after washing of the treated specimen was also examine. It is get that biopolymer ultraviolet finish able to accurately given to modal/cotton Knitted fabrics. Biopolymer finished specimen showed similar UPF value, providing excellent ultraviolet protection when compared to the untreated specimen. The ultraviolet tests specify a significant improvement in the UV absorbing action in the biopolymer treated fabrics.
\end{abstract}

Keywords: Modal/cotton fabric, ultraviolet protection, biopolymer, FT-IR,FESEM

\section{INTRODUCTION}

Textiles include such a importance position in our regular breathes that everyone needs to know about some point of textile increase. 'Sustainability' in textiles to the practice of environmental and friendly methods for the production of fabrics. This means establishing practices that preserve energy and natural wealth and reduce negative environmental, economic and social property.

Modal fabric is semi-synthetic, it is impossible to have this fabric certified as organic. Modal fabric is slightly more environmentally friendly than the viscose rayon production process. This increased environmental benefit is mainly provided by the lesser concentrations of caustic soda that are used to dissolve, Cotton is the most popular and highly used fiber amongst the fibers, and adopted by the consumers all over the world right from the ancient period of development. It is known for its absorbing feel, comfort and flexibility

The customers want products that allow them to stay in the sun for a longer period of time. Most products are under attack at a specific market and nearly every company has a complete choice of products. The most recent introductions have paying attention on products for athletes children,, or for those who want UVA protection.

In current years, big attention has been devoted to biopolymers because of their biocompatibility and biological functions and consequently, they are used in textile, biomedical and pharmaceutical fields. Some marine and land animals such as snail and fishes possess some compounds which exhibit antimicrobial activity. Anchantina fulica effective natural antimicrobial agents and which are polymers that are generated from renewable natural sources are often biodegradable and non toxic toproduce. The work addresses the request of Anchantina fulica biopolymer on modal/cotton knitted fabrics to develop ultraviolet resistant fabric appropriate for clothes and thereby protecting it from ultraviolet radiation.

\section{MATERIALS AND METHODS}

The Modal and cotton fabric has high-quality properties of withstanding severe treatments especially, through dyeing and Priniting For the study, 32's combed modal and cotton yarn were made of knitted Fabric . The term 'pretreatment' summarizes all types of basic finishes such as desiring, scouring and bleaching the fabric. The pretreatment processes such as biodesizing, bioscouring and biobleaching were done on modal/cotton blended fabrics.

\section{Extraction Of Anchantina fulica From Shell Of The land Sail}

The Anchantina fulica exoskeletons collected were placed in Ziploc bags and refrigerated overnight. Moisture content was determined on the Anchantina fulica waste by first crushing exoskeletons into smaller pieces using a meat tenderizer. Approximately ten grams of wet samples of crushed Anchantina fulica exoskeletons were placed on foil paper and measured using a Mettle balance. There were five measurements made of the weight of the wet crushed. 
Anchantina fulica exoskeletons samples. The samples were then labeled and oven-dried for four consecutive days at $65^{\circ} \mathrm{C}$ until constant weight.

\section{MEASUREMENT OF ULTRAVIOLET PROTECTION FINISH}

The standard test method is used to establish the Ultraviolet radiation blocked or transmitted by textile fabrics intended to be used for Ultraviolet Protection. This process provides procedures for measuring this fabric property with specimens in either the dry and wet status. Tested two specimens from each sample for the wet and dry testing. Each specimen was cut for at least $4.0 \mathrm{X} 4.0$ inches. Ultraviolet Protection issue is measured by the ratio of the average effective Ultraviolet radiation (UV-R) irradiance transmitted and calculated air to the standard effective UV-R irradiance transmitted and calculated through fabric.

Standard chart for UPF rating for the fabric

\begin{tabular}{|l|l|l|}
\hline $\begin{array}{l}\text { PROTECTION } \\
\text { CATEGORY }\end{array}$ & $\begin{array}{l}\text { \% ULTRAVIOLET } \\
\text { RADIATION } \\
\text { BLOCKED }\end{array}$ & UPF RATING \\
\hline Poor & Below 93.2 & $0-10$ \\
\hline Good & $93.3-95.9$ & 15 to 20 \\
\hline Very Good & $96.0-97.4$ & 25 to 35 \\
\hline Excellent & 97.5 or more & Above 40 \\
\hline
\end{tabular}

\section{ASSESS UV PROTECTION ACTION IN THE TREATED FABRIC BY (AATCC 183-1999)}

The two finished fabric specimens were decide using by UV transmittance and then UV visible spectrophotometer. This standard test method was used to determine the UV radiation blocked or transmitted by textile fabrics intended to be used for UV protection. In this UV protection, analyzer specimens were tested in both wet and dry state.

Field Emission Scanning Electron Microscope (FESEM)

The surface morphology of proscribed and finished fabric samples was analyzed by field emission scanning electron microscope. This scanning electron microscope radiates high energy electrons in a paying attention beam to create a variety of signals on the surface of the fabric samples.

Fourier-Transform Infrared Spectroscopy (FT-IR)

Fourier transform infrared spectroscopy (FT-IR) was an scientific tool to identify the nature of chemicals that are glaze on the fabric specimen. The Fourier Transform Infrared spectrometer is most useful for identifying active chemical ingredient whether organic or inorganic.

\section{UV analysis of finished fabric}

\section{RESULTS AND DISCUSSION}

This ultraviolet protection of Modal/Cotton treated sample with Anchantina fulica bioplymer showing $95.3 \%$ of ultraviolet radiation blockage showing good protection type and 50++ of UPF range

Analysis of the sample finished with the Anchantina fulica Biopolymer by Fourier Transmission Scanning

\begin{tabular}{|c|c|c|c|c|}
\hline Sl.no & Fabric Sample & UPF Range & $\begin{array}{l}\% \mathrm{UV} \\
\text { Radiation } \\
\text { Blocked }\end{array}$ & $\begin{array}{l}\text { Protection } \\
\text { Category }\end{array}$ \\
\hline 1 & $\begin{array}{l}\text { Controlled } \\
\text { (Untreated } \\
\text { sample) }\end{array}$ & 0 & 0 & 0 \\
\hline 2 & $\begin{array}{l}\text { Anchantina } \\
\text { fulica }\end{array}$ & $50++$ & $95.3 . \%$ & Good \\
\hline
\end{tabular}

\section{Electron Microscope (FESEM)}

The outside topography of the Anchantina fulica Biopolymer finished fabric sample was experimental using Fourier transmission scanning electron microscope (FESEM). The quality of Anchantina fulica sample finished by direct application method was analyzed. 


\section{International Advanced Research Journal in Science, Engineering and Technology}

Vol. 8, Issue 9, September 2021

DOI: 10.17148/IARJSET.2021.8920

\section{Untreated Sample}
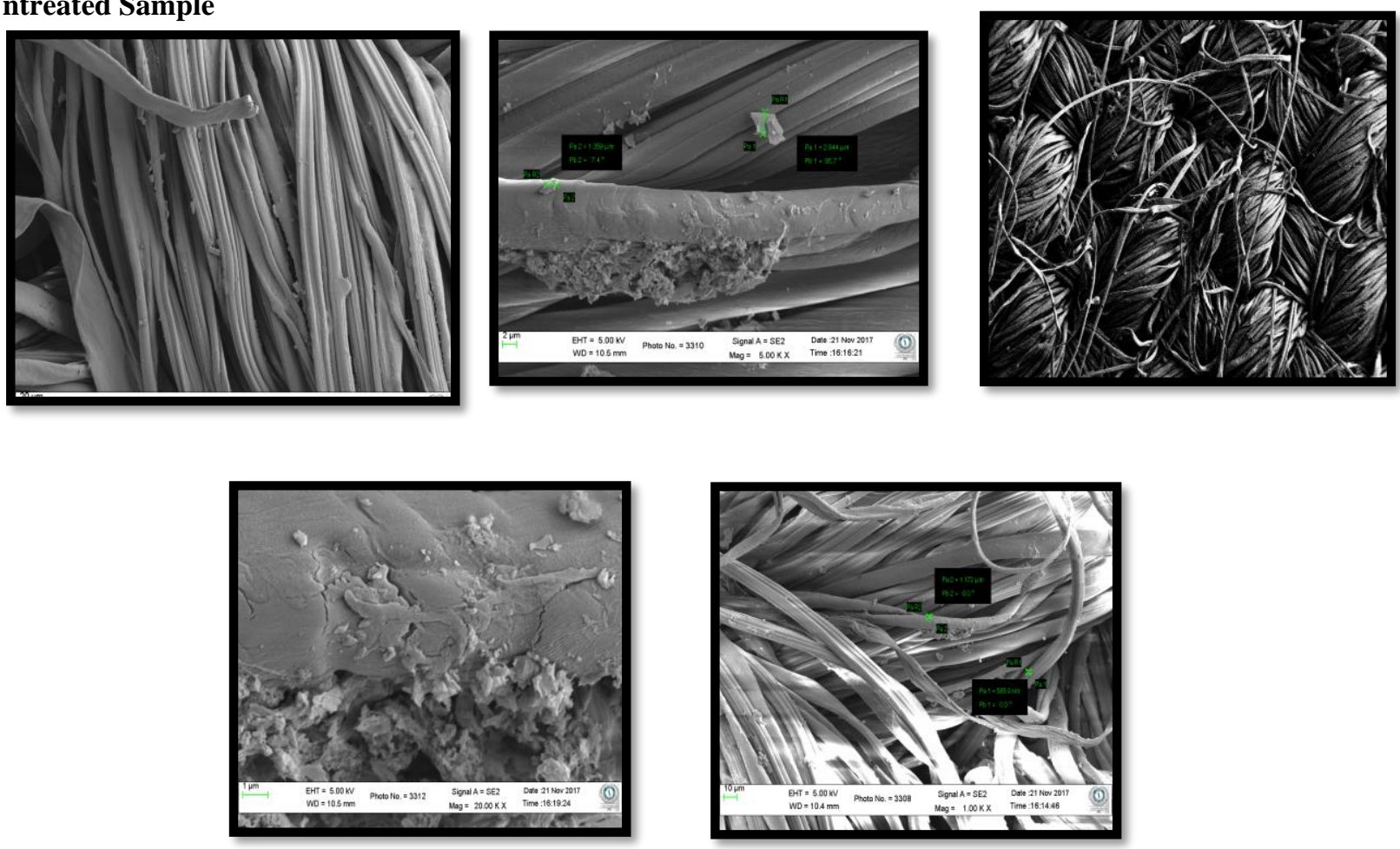

\section{Treated Sample}

The Fourier transmission scanning electron microscopic images of bamboo/cotton woven fabric finished with Anchantina fulica Biopolymer showed the clear deposition of extract on the inner surface of the fabric whereas, in untreated sample there is no deposition on the fabric. The imaging was done with different magnifications like $1.24 \mathrm{KX}, 1.30 \mathrm{KX}$ and $40.00 \mathrm{KX}$.

Analysis of Fourier-Transform Infrared Spectroscopy (FT-IR) Anchantina fulica Biopolymer fabric sample The functional group of the Anchantina fulica Biopolymer finished fabric sample was identified by using Fouriertransform infrared spectroscopy (FT-IR

The FT-IR spectrum was used to discover the functional group of the different components based on the peak value in the area of infrared radiation. The functional group identification is based on the FT-IR peaks attributed to the stretching and bending vibrations. The outcome of FT-IR analysis revealed the presence of alkenes, $1^{\circ}, 2^{\circ}$ amines, aliphatic amines, alkynes, Alkenes, , aromatics alkynes and nitro compound.

\section{CONCLUSION}

The current research is intended at developing ultraviolet protection finish on Modal/cotton fabric using biopolymer extract. Textiles, when covered with the selected biopolymer showed higher UPF rating touching skin and this necessitates the development of stronger natural absorbers in its place of chemically coated fabric.

\section{REFERENCES}

1. Azevedo, (1999) JS, Viana NS, Jr, ViannaSoares CD. UVA/UVB sunscreen determination by second-order derivative ultraviolet spectrophotometer. Farmaco; 54:573-8.

2. Sathyanarayanan K.S., Darshan B.S., Balaji R., (2009) Studies on the characterization of Biosealant properties of Bacillus sphaericus, International Journal of Engineering Science and Technology, Volume 2, Issue 3, Pp:270-277

3. Toomula Srilatha; Jyothi Sree C.. "Survey on Plant Diseases Prediction using Machine learning for better Crop Yield". International Research Journal on Advanced Science Hub, 3, Special Issue 6S, 2021, 1-5.

4. Malik Prem, (2007), "Role of Cotton as Major Textile Raw Material", Textile Magazine, Vol. 48, No. 4, Pp:12 